\title{
Patterns of Parental Rearing Styles and Child Behaviour Problems among Portuguese School-Aged Children
}

\author{
Ana I. F. Pereira $\cdot$ Cristina Canavarro • \\ Margarida F. Cardoso - Denisa Mendonça
}

Published online: 24 December 2008

(C) Springer Science+Business Media, LLC 2008

\begin{abstract}
The majority of studies investigating the effects of parental behaviour on the child's adjustment have a dimensional approach. We identified the existence of various patterns in parental rearing styles and analysed the relationship between different parenting patterns and behavioural problems in a group of school-aged children. A longitudinal, multi-informant study was conducted. The sample consisted of 519 school-aged children from the Portuguese general population. Parental rearing styles were measured using the EMBU-C, a questionnaire that evaluates children's perception of parental rearing dimensions. The assessment of child behavioural problems included the evaluation of internalizing and externalizing problems, and data from multiple reporters (parents and teacher). One year later, after a school transition, the adjustment of a subsample of 220 children was evaluated again. Cluster analysis identified four types of parental rearing styles: low support, supportive-controller, rejecting-controller, and supportive. In both assessment periods, low support and rejecting-controller parenting patterns showed higher levels
\end{abstract}

\footnotetext{
A. I. F. Pereira $(\square)$

Instituto de Psicologia Cognitiva, Desenvolvimento Vocacional e Social (IPCDVS), Coimbra University, Rua do Colégio Novo, Apartado 6153, 3001-802 Coimbra, Portugal

e-mail: aifreitaspereira@sapo.pt

C. Canavarro

Faculty of Psychology and Educational Sciences, Coimbra University, Coimbra, Portugal
}

M. F. Cardoso · D. Mendonça Institute of Biomedical Sciences Abel Salazar, ICBAS, Porto University, Porto, Portugal of behavioural problems than the supportive and supportive-controller parenting patterns. These patterns show significant differences between them regarding behavioural problems and have a higher predictive value regarding externalizing problems (versus internalizing problems).

Keywords Parental rearing styles - Cluster analysis . Internalizing problems $\cdot$ Externalizing problems . School-aged children

\section{Introduction}

The relationship between parents and children plays a central role in understanding the behavioural and psychosocial development of the child (Cummings et al. 2000). For many decades, it was believed that parental rearing could be adequately described by two main dimensions: the first described as care, referring to acceptance, warmth, responsiveness, and, on the other hand, rejection; and the second one described as control, referring to multiple behaviours relating to child discipline and management, supervision and overprotection (Cummings et al. 2000; Maccoby and Martin 1983).

Until now, the effect of parental rearing behaviour and of these two dimensions in particular, on children's behaviour and social adjustment, has been studied using mainly a dimensional approach. This approach has the advantage of considering the unique and specific contributions of each dimension of parental rearing behaviour to the child's adjustment.

Several studies suggest that negative parental rearing behaviours may increase the risk of adjustment problems. Parental rejection and lack of parental warmth were consistently found to relate to children's externalizing and 
internalizing problems (Caron et al. 2006; Chen et al. 2000; Gracia et al. 2005; Javo et al. 2004; Muris et al. 2003) as well as low academic and social competences (Chen et al. 2000; Morrison and Cooney 2002).

Empirical literature suggests that the relationship between parental control and the child's outcome may not be straightforward (Chen et al. 2000). The study of parental control effects is complex and requires various factors to be considered. In the first place, this dimension relates to a great heterogeneity of behaviours, including communication of a set of rules, enforcement of the rules, monitoring, supervision, and overprotection. Also, there are differences in the way specific behaviour control strategies are employed, and in the case of negative disciplinary techniques, this depends on the severity, frequency, and intensity of the disciplinary practices (Deater-Deckard and Dodge 1997). In the second place, these behaviours have different meanings depending on the child's characteristics (e.g. child's developmental level) (Castro et al. 1993) and context characteristics (e.g. culture) (Deater-Deckard et al. 1996).

The family's emotional climate is an important context characteristic that determines the effects of parental control (Chen et al. 2000; Darling and Steinberg 1993). On the one hand, children that perceive high emotional support are more likely to regard parental control as legitimate and to perceive this control has a result of parental involvement and care. On the other hand, high parental control in the context of a poor emotional climate may be perceived by the child as an attempt by the parents to restrain personal autonomy and to retain power in the relationship, which may increase the child's resistance to parental authority and attempt to control. Therefore, as Cummings et al. (2000) stated “children's adjustment is not simply a function of additive, unique combinations of specific parenting characteristics; rather, it is a function, in part, of children's experience with different patterns or profiles of parenting characteristics" (p. 170).

Several authors have favoured the pertinence of the typological approach in the study of parental rearing behaviour. This approach is aimed at achieving a more holistic understanding of the patterns and the environment that make up the context for the occurrence of certain parental behaviours (Steinberg et al. 1994).

The typological approach is based on two main assumptions concerning the nature of parental behaviour (Caron et al. 2006; O'Connor 2006). Firstly, parental behaviours are correlated with each other (for example, parents who are affectionate also use positive control strategies). Therefore, parental behaviours should be considered as a whole and not isolatedly. Secondly, the effects of a dimension of parental behaviour depend on the presence (or absence) of another dimension of parental behaviour, and therefore the typologies should take into account multiple parental behaviours. This means that the typological approach has an increased ecological validity, since it describes parental behaviours that occur naturally and simultaneously, with the advantage of emphasising the interaction effects between the different variables and the way the effect of a certain dimension is affected by the levels of the other parental behaviour dimension (Stewart and Bond 2002).

Following this line of study, Diana Baumrind (1967, 1971) developed a typology composed of three parenting types, authoritative, authoritarian, and permissive. The authoritative parenting type corresponds to a constellation of parental behaviours, which simultaneously involves flexibility and responsiveness to the child's needs and the establishment of restrictions and appropriate behavioural patterns. Authoritarian parents attempt to shape, control, and evaluate children's behaviour and attitudes according to a defined standard of conduct, usually an absolute standard. When the child's actions or beliefs conflict with the parent's standards of acceptable behaviour, they favour punitive and forceful measures. The permissive parenting type corresponds to behaviours of affection and responsiveness towards the child, without setting restrictions for appropriate behaviour. Subsequently, and based on the four-step classification developed by Maccoby and Martin (1983), Baumrind (1989, 1991a, 1991b) added a fourth type, neglectful (uninvolved). The neglectful parenting type corresponds to the parents who have little responsiveness to their children and have little concerns for their needs or behaviour. The results of Baumrind's study (1967, 1971, 1989, 1991a, 1991b) clearly suggested the advantages of an authoritative pattern, for both sexes and different stages of development (pre-school age, school age, and adolescence).

Subsequently, a few studies (Brenner and Fox 1999; Dornbusch et al. 1987; Lamborn et al. 1991; Mandara and Murray 2002) using a typological approach tried to study the relationship between parental rearing styles, psychopathology, and competence in childhood and in adolescence. The results of these studies, like the findings of Baumrind, suggested that the authoritative type is the most advantageous and the one which promotes a more competent development. Nevertheless, most of these studies defined the different patterns of parental rearing styles using cut-off scores and the vast majority relied on a single reporter.

The first goal of this study was to identify patterns of rearing behaviour perceived by Portuguese school-aged children, based on three parental rearing dimensions: Warmth, Rejection, and Control Attempts. In this study we adopted a typological approach to parental rearing styles using cluster analysis. This methodology has an advantage over other methodologies as it identifies natural groups 
existing in the population, without imposing a categorization based on artificial cut-off scores (Steinberg et al. 1994)

It should be pointed out that the typology used for this study considered the parental rearing styles of both mother and father simultaneously. Some studies reported differences between the mother and the father's parenting (e.g. Paulson and Sputa 1996; Shek 2000) and Baumrind (1989) found a pattern, called traditional, which was characterized by a structural role differentiation between mothers and fathers: mothers were highly responsive but relatively undemanding, whereas fathers were highly demanding but frequently coercive and unresponsive. Therefore, including the assessment of both the mother and the father's parental rearing styles, it was important to explore the existence of a pattern, characterized by diverging parenting profiles, and its relation to the child's outcome.

The second goal of this study was to explore whether different patterns of parental rearing styles were related to the child's adjustment, using multiple informants to assess two main broadband domains of child psychopathological problems, namely internalizing problems (including behaviour such as withdrawal, anxiety or depression) and externalizing problems (including aggressive and delinquent behaviour). In this study we sought to examine the specific relationships between different patterns of parental rearing styles and internalizing and externalizing problems. The question as to whether there is some specific relationship between parenting and different forms of psychopathology, namely internalizing and externalizing problems, was not fully addressed in the previous empirical studies. The majority of studies that evidenced significant associations between disturbed parental rearing styles and both internalizing and externalizing problems did not take into account correlations among these two forms of psychopathology. Therefore, study results that suggest a nonspecific relationship between parenting behaviours and internalizing or externalizing problems may actually represent indirect effects of parenting behaviour through nonassessed covariance between these two forms of psychopathology (Caron et al. 2006).

As far as we know, this was also the first study that analyses associations between the adjustment of schoolaged children and different patterns of parental rearing styles identified by cluster analysis. Middle childhood has been frequently described as a period of relative calm for families, compared to infancy and adolescence (Shanahan et al. 2007). Yet children undergo important changes in different developmental domains that have implications for the relationship they establish with their parents. When children start going to school there is a decline in the amount of time they spend in their parent's presence and in their interaction rates. Also, parental control over the child's behaviour undergoes considerable change, relying less on direct supervision and more on developing a system of "co-regulation" (Maccoby 1984). Nevertheless, parents continue to be perceived by children as their main providers of different kinds of support (emotional, instrumental, informational and companionship) (Pereira et al. 2005) and remain as an important support for the successful accomplishment of the emerging developmental tasks in middle childhood, including school adjustment, development of peer relationships, and formation of friendships.

In this study, the associations between parental rearing styles and the child's behavioural problems were explored cross-sectionally and prospectively, submitting a sub-group of children from the original sample to a second assessment one year after the first assessment. This type of study, although not showing the effect of causal relationships, provides a better support than the cross-sectional studies of impact of parental rearing in children's adjustment. Furthermore, this longitudinal study was conducted in the context of a significant life event: school transition. It follows children during the occurrence of a school transition from primary to middle school. In the Portuguese educational system, the transition between primary and middle school can be especially challenging as it often subjects children to several changes (e.g. transition to a larger school, change from one teacher to multiple teachers, disruption of social relations). Garmezy (1990) referred the importance of the existence of short longitudinal studies that investigate the occurrence of specific stressful life events that can disrupt an individual's pattern of adjustment. Therefore, this study aimed at understanding the role of parental rearing styles on children's adaptation after a school transition.

\section{Methods}

\section{Participants}

The sample comprised 519 children from the general population. Children were attending primary schools in various geographical areas of Portugal. In the first assessment period, children were aged between 8 and 11 (Mean $=8.93, \mathrm{SD}=0.77$ ). The group showed a balanced ratio of female $(52 \%)$ and male children. The majority of children belonged to intact nuclear families $(88.8 \%)$, had one or more siblings $(79 \%)$ and lived in semi-urban or urban areas $(83.8 \%)$. The children came from families of diverse socio-economic levels (low-33.3\%, middle$32.0 \%$, medium-high and high-34.7\%). In the second assessment period, the sub-sample comprised 220 children, who had attended the 4th grade in the previous year and had passed to the 5th grade and moved to a new school. 
Procedure

This study was conducted in 41 elementary schools. Permission for the study was granted by the Regional Departments of Education, the Executive boards of the schools and the primary school teachers. Parents of 3 to 11 students, randomly selected from each class, were invited to participate in the project. From all the families approached, only approximately $5 \%$ of the parents did not agree to participate. All parents gave their written informed consent.

The child questionnaires were conducted at the schools by trained interviewers. Children were told what the goal of the interview was and that the confidentiality of their answers was assured. After ensuring that the example items were fully understood, the children were asked to complete both instruments autonomously. Parents and teachers answered the instruments autonomously. The adjustment assessment instruments were applied again one year after the first assessment, following the same methodology.

\section{Instruments}

\section{EMBU-C (Egna Minnen av Barndoms Uppfostran: "My} Memories of Upbringing”, Castro et al. 1993)

The EMBU-C is a questionnaire originally developed in Spanish for the purpose of measuring children's perceptions of parental rearing behaviours. In the present study, the Portuguese version of EMBU-C (Canavarro and Pereira 2007a) was used. This version evaluates parental rearing behaviours in three dimensions: Emotional Warmth (14 items), Rejection (eight items), Control attempts (ten items). The Portuguese version of EMBU-C contains 32 items, with answers on a 4-point Likert scale $(1=$ No, never, 2 = Yes, but seldom, $3=$ Yes, often, $4=$ Yes, most of the time). For each item, children first rated the father's and then the mother's rearing behaviour.

Using the present data, the internal consistency for the Emotional Warmth scale $(\alpha=0.85$ for father and $\alpha=0.82$ for mother) was good, and for the Rejection $(\alpha=0.64$ for father and $\alpha=0.65$ for mother) and Control attempts scales ( $\alpha=0.65$ for father and $\alpha=0.62$ for mother) was moderate. The mean inter-item correlation range $(0.14$ 0.29 ) for the six scales was considered satisfactory. Fourweek test-retest analyses were conducted on a sub-sample of children. Test-retest correlation coefficients were 0.74 for fathers' emotional support, 0.70 for mothers' emotional support, 0.73 for fathers' rejection, 0.70 for mothers' rejection, 0.68 for fathers' control attempts, and 0.56 for mothers' control attempts. Pearson correlations were found to be statistically significant between the corresponding scales of EMBU-C and the Portuguese parents' version of
EMBU (EMBU-P, Canavarro and Pereira 2007b) although within the low $(0.11)$ to moderate $(0.30)$ range.

\section{CBCL (Child Behaviour Checklist; Achenbach 1991a)}

Parental ratings of child conduct were obtained by applying the Portuguese version of CBCL (Fonseca et al. 1994). The CBCL is a questionnaire to be completed by parents of children between the ages of 4 and 18. The problem section used in this study contains 118 items on behavioural and emotional problems during the previous 6 months. Parents were requested to circle 0 if the problem item was not true, 1 if the item was somewhat or sometimes true and 2 if the item was very true or often true.

In the present study we considered the classifications of the two broadband scales: internalizing ( $\alpha=0.84$ for the first assessment and $\alpha=0.85$ for the second assessment) and externalizing problems $(\alpha=0.88$ for the first assessment and $\alpha=0.90$ for the second assessment). Correlations between the scores of both assessment periods were computed to analyse 1 year stability of the behavioural problem variables. All of the stability coefficients were high $(0.52$ for the internalizing scale and 0.72 for the externalizing scale).

\section{TRF (Teacher Report Form; Achenbach 1991b)}

Teacher's ratings of child behaviour were obtained by applying the Portuguese version of TRF (Fonseca et al. 1995). The TRF problem section is composed of 118 items on behavioural and emotional problems. Teachers indicated the occurrence of the behaviour described in each item, during the previous two months, on a scale of 0 (not true) to 2 (very true or often true).

The classifications of the two broadband scales, internalizing ( $\alpha=0.89$ for the first assessment and $\alpha=0.86$ for the second assessment) and externalizing problems ( $\alpha=0.95$ for the first assessment and $\alpha=0.94$ for the second assessment) were used for the present study. For this sample, the 1 year stability coefficients were 0.15 for the internalizing scale and 0.59 for the externalizing scale.

\section{Statistical Analysis}

Cluster analysis was used to empirically determine whether parental rearing styles would reflect distinct patterns of parenting. The six parental rearing style variables, corresponding to the three dimensions of parental rearing styles (emotional warmth, rejection, control attempts) evaluated separately for mothers and fathers, were standardized to eliminate the effects of different variances.

In order to examine the characteristics of the clusters of parental rearing styles, a multivariate analysis of variance 
(MANOVA) was computed on the six parenting style scales, with the cluster variable serving as the factor. Afterwards, the associations between parental rearing patterns and children's behavioural problems were examined. Two separate multivariate analyses of variance (MANOVA) were computed, with the cluster variable (type of parental rearing styles) and child's gender as the betweensubjects factor, and the problem behaviour variables as the dependent variables: the first MANOVA was computed on behavioural problems (internalizing and externalizing) evaluated by teachers and the second MANOVA was computed on behavioural problems (internalizing and externalizing) evaluated by parents. Previously, the four problem behaviour variables had been submitted to logarithmic transformation in order to achieve analyses' assumptions. These analyses were repeated for the behavioural problems assessed at the second assessment period. Analyses of covariance (ANCOVA) were performed in order to examine the effects of parental rearing types on internalizing problems evaluated by parents controlling for the effects of the externalizing problems assessed by parents.

\section{Results}

Identification of the Types of Parental Rearing Styles through Cluster Analysis

In the first place, it was necessary to decide the number of clusters that would be retained. This is the most difficult decision in cluster analysis, and has traditionally been the Achilles' heel of cluster analysis (Mandara 2003). In order to accomplish this purpose, 20 samples that resulted from ten random divisions of the total data in two equal size samples were first submitted to hierarchical cluster analysis. This procedure was intended to identify the number of potential clusters by examining the dendrogram. The analysis of the 20 dendrograms suggested the existence of three to six clusters.

The number of clusters to be retained was decided by means of a replication analysis. A modification of the replication method developed by McIntyre and Blashfield (1980), described by Mandara (2003), was applied. The method of replication was as follows: first, a full cluster analysis is performed on one of the samples (sample A). Then, a full cluster analysis is performed on the paired sample B. This is followed by the classification of sample $\mathrm{B}$ according to the centroids derived from sample A, and, finally, the agreement is computed between the two sample B solutions using Cohen's Kappa. The more agreement is found between the two solutions, the more reliable the cluster solution is. This cross validation procedure was repeated ten times for each potential number of clusters (three, four, five and six clusters). The four cluster solution was retained, as it presented the largest mean Kappa $(K=0.77)$.

Then, a two stage method for the cluster analysis was used for the total sample. The first stage was an agglomerative hierarchical cluster analysis. The hierarchical algorithm chosen was Ward's method, since it seems to be the most robust to various types of data (Mandara 2003). This method attempts to minimize the Sum of Squares between each cluster at each step. The Squared Euclidean distance was chosen as a measure of dissimilarity. A $K$ means iterative cluster analysis using the initial four cluster centroids obtained from the hierarchical cluster analysis was then performed.

Description of the Four Types of Parental Rearing Styles Perceived by the Children

The MANOVA showed significant multivariate effect (Roy's Largest Root $=2.09, F_{6,512}=177.90, P<0.001$, $\eta^{2}=0.68$ ). All the subsequent ANOVAs also showed significant effects of the parental rearing type factor. In order to better understand the differences between the empirical clusters, Tukey HSD (equal variances assumed) or Tamhane (equal variances not assumed) tests were used to identify which groups differed from each other in each dependent variable. These analyses show that the four types of parental rearing styles are distinct for the six variables of the parental rearing styles (Table 1).

The four parental rearing types were named according to their more outstanding characteristics. The low support parenting type shows the lowest values of emotional support from the father and the mother, showing also low levels of rejection, and the lowest levels of control attempts by both parents. The supportive-controller type shows high levels of emotional support and of control attempts by both the father and mother. This type also shows low levels of rejection. The rejecting-controller parenting pattern shows the highest levels of rejection and high levels of control attempts by both the father and mother. This parenting type also shows lower levels of emotional support when compared to the supportive and supportive-controller parenting types. Finally, the supportive type shows high levels of emotional support from both parents but low levels of rejection and control attempts.

The supportive-controller and supportive parenting types occur most frequently (in 29.5 and $36.4 \%$ of the cases, respectively), followed by the low support pattern, in $18.3 \%$ of the cases, and by the rejecting-controller type, in $15.8 \%$ of the cases. As it can be seen, mothers' and fathers' parental rearing profiles are very similar in all four patterns, although children reported significantly more emotional support and 
Table 1 Means and standard deviation scores for the six variables of parental rearing styles by the four parenting types, and ANOVA results

\begin{tabular}{|c|c|c|c|c|c|c|}
\hline \multirow[t]{2}{*}{ Variable } & \multicolumn{4}{|l|}{ Parental types } & \multirow[b]{2}{*}{$\mathrm{F}(3,515)$} & \multirow[b]{2}{*}{$\eta^{2}$} \\
\hline & $\begin{array}{l}\text { Low support } \\
N=95 \\
\mathrm{M}(\mathrm{SD})\end{array}$ & $\begin{array}{l}\text { Supportive-controller } \\
N=153 \\
\mathrm{M}(\mathrm{SD})\end{array}$ & $\begin{array}{l}\text { Rejecting-controller } \\
N=82 \\
\mathrm{M}(\mathrm{SD})\end{array}$ & $\begin{array}{l}\text { Supportive } \\
N=189 \\
\mathrm{M}(\mathrm{SD})\end{array}$ & & \\
\hline \multicolumn{7}{|l|}{ Father } \\
\hline Emotional Support & $32.44(5.61)^{\mathrm{d}}$ & $48.07(4.37)^{\mathrm{a}}$ & $43.33(6.75)^{\mathrm{c}}$ & $45.16(4.50)^{\mathrm{b}}$ & $197.29 * * *$ & 0.54 \\
\hline Rejection & $11.28(2.29)^{\mathrm{b}}$ & $11.24(1.82)^{\mathrm{b}}$ & $17.38(2.73)^{\mathrm{a}}$ & $10.46(1.80)^{\mathrm{c}}$ & $229.18 * * *$ & 0.57 \\
\hline Control attempts & $18.80(4.05)^{\mathrm{d}}$ & $28.10(3.20)^{\mathrm{a}}$ & $26.40(4.48)^{\mathrm{b}}$ & $20.61(2.96)^{\mathrm{c}}$ & $204.54 * * *$ & 0.54 \\
\hline \multicolumn{7}{|l|}{ Mother } \\
\hline Emotional Support & $34.97(5.24)^{\mathrm{d}}$ & $48.53(4.18)^{\mathrm{a}}$ & $44.49(6.75)^{\mathrm{c}}$ & $46.41(3.99)^{\mathrm{b}}$ & $169.73 * * *$ & 0.50 \\
\hline Rejection & $11.77(2.60)^{\mathrm{b}}$ & $11.30(1.95)^{\mathrm{b}}$ & $17.65(3.08)^{\mathrm{a}}$ & $10.47(1.72)^{\mathrm{c}}$ & $211.93 * * *$ & 0.55 \\
\hline Control attempts & $20.69(4.07)^{\mathrm{b}}$ & $28.94(2.97)^{\mathrm{a}}$ & $27.86(4.28)^{\mathrm{a}}$ & $21.86(3.28)^{\mathrm{b}}$ & $177.70 * * *$ & 0.51 \\
\hline
\end{tabular}

*** $P<0.001$

Means sharing a common subscript were not significantly different form each other (Tukey HSD or the Tamhane post-hoc procedure for multiple comparisons)

control attempts from the mother than from the father in all parental rearing types, and significantly more rejection from the mother than from the father in the low support type.

Associations Between the Four Types of Parental Rearing Styles and the Children's Adjustment

Adjusting for the effects of child gender, the MANOVA revealed a significant multivariate effect of the types of parental rearing styles on internalizing and externalizing problems assessed by teachers at the first assessment period (Roy's Largest Root $=0.02, \quad F_{3,514}=2.71, P=0.045$, $\eta^{2}=0.02$ ), and at the second assessment period (Roy's Largest Root $=0.06, \quad F_{3,215}=4.58, \quad P=0.004, \quad \eta^{2}=$ 0.06). Concerning the internalizing and externalizing problems assessed by parents and also controlling for child gender, the MANOVA revealed a significant effect both in the first (Roy's Largest Root $=0.06, \quad F_{3,514}=10.85$, $\left.P<0.001, \eta^{2}=0.06\right)$ and the second assessment periods (Roy's Largest Root $=0.16, F_{3,215}=11.29, P<0.001$, $\left.\eta^{2}=0.14\right)$. There was no significant interaction between child gender and the four patterns of parental rearing styles, so the interaction was not included in the analysis.

Table 2 shows the results of the subsequent ANOVAS and the significant findings regarding relationships between the four types of parental rearing styles and adjustment problems. It also presents the mean and standard deviation of the t-scores for each parenting type.

In both transversal analysis and prospective analysis, we found significant effects of the parenting types on all indicators of externalizing problems, controlling these effects for child's gender. Only one significant effect of the parenting types on the internalizing problems was found. This effect was for parent's assessment (and not the teacher's assessment) of internalizing problems and only for the first evaluation (and not the second evaluation). However, because externalizing problems and internalizing problems are correlated, an ANCOVA was done to examine whether the significant effects of parental rearing types on internalizing problems evaluated by parents persisted after including externalizing problems assessed by parents as covariate. The effect of parenting patterns became insignificant in ANCOVA analysis, suggesting that the significant association between parenting patterns and internalizing problems was due to an indirect effect through externalizing problems.

Tukey HSD (equal variances assumed) or Tamhane (equal variances not assumed) post-hoc tests were conducted to further specify the basis of significant effect. These analyses reveal that the supportive and supportivecontroller parenting types seem to be associated with lower levels of externalizing problems, and, on the other hand, the rejecting-controller and low support parenting types show higher externalizing problems.

\section{Discussion}

Two research goals were pursued in this study. Firstly, the identification of different patterns of parental rearing styles through cluster analysis, and, secondly, the examination of the relationship between the different types of parental rearing styles and the adjustment of Portuguese schoolaged children.

The cluster analysis revealed four types of parental rearing styles. A first parenting type, named low support (18.3\%), shows the lowest values for emotional support from father and mother, also showing low levels of rejection and control attempts from both parents. A second parenting pattern, supportive-controller (29.5\%), characteristically 
Table 2 Mean and standard deviation $t$-scores for behaviour problems variables by the four parenting types, and ANOVA results (using logarithmic transformations) controlling for the effects of child's sex

\begin{tabular}{|c|c|c|c|c|c|c|}
\hline \multirow{2}{*}{$\begin{array}{l}\text { Emotional and behavioural } \\
\text { problems }\end{array}$} & \multicolumn{4}{|l|}{ Parental types } & \multirow[t]{2}{*}{$\mathrm{F}(3,514)^{\mathrm{A}}$} & \multirow[t]{2}{*}{$\eta^{2}$} \\
\hline & $\begin{array}{l}\text { Low support } \\
N=95 \\
\mathrm{M}(\mathrm{SD})\end{array}$ & $\begin{array}{l}\text { Supportive-controller } \\
N=153 \\
\mathrm{M}(\mathrm{SD})\end{array}$ & $\begin{array}{l}\text { Rejecting-controller } \\
N=82 \\
\mathrm{M}(\mathrm{SD})\end{array}$ & $\begin{array}{l}\text { Supportive } \\
N=189 \\
\mathrm{M}(\mathrm{SD})\end{array}$ & & \\
\hline \multicolumn{7}{|l|}{ 1st assessment period } \\
\hline \multicolumn{7}{|l|}{ Teachers (TRF) } \\
\hline Internalizing problems & $50.73(1.22)$ & $50.17(0.74)$ & $50.07(0.93)$ & $49.47(0.75)$ & 0.80 & $<0.01$ \\
\hline Externalizing problems & $51.72(1.10)^{\mathrm{a}}$ & $49.52(0.77)^{\mathrm{a}, \mathrm{b}}$ & $52.33(1.45)^{\mathrm{a}, \mathrm{b}}$ & $48.51(0.58)^{\mathrm{b}}$ & $2.71 *$ & 0.02 \\
\hline \multicolumn{7}{|l|}{ Parents (CBCL) } \\
\hline Internalizing problems & $51.50(1.15)^{\mathrm{a}, \mathrm{b}}$ & $49.07(0.76)^{\mathrm{b}}$ & $53.06(1.17)^{\mathrm{a}}$ & $48.67(0.67)^{\mathrm{b}}$ & $5.01 * * *$ & 0.03 \\
\hline \multirow[t]{2}{*}{ Externalizing problems } & $53.82(1.25)^{\mathrm{a}}$ & $48.41(0.69)^{\mathrm{b}}$ & $54.54(1.19)^{\mathrm{a}}$ & $47.40(0.60)^{\mathrm{b}}$ & $10.77 * * *$ & 0.06 \\
\hline & $\begin{array}{l}N=40 \\
\mathrm{M}(\mathrm{SD})\end{array}$ & $\begin{array}{l}N=56 \\
\mathrm{M}(\mathrm{SD})\end{array}$ & $\begin{array}{l}N=31 \\
\mathrm{M}(\mathrm{SD})\end{array}$ & $\begin{array}{l}N=93 \\
\mathrm{M}(\mathrm{SD})\end{array}$ & $\mathrm{F}(3,215)^{\mathrm{A}}$ & $\eta^{2}$ \\
\hline \multicolumn{7}{|l|}{ 2nd Assessment period } \\
\hline \multicolumn{7}{|l|}{ Teachers (TRF) } \\
\hline Internalizing problems & $51.30(2.16)$ & 49.15 (1.39) & $50.08(1.63)$ & $49.42(0.81)$ & 0.76 & 0.01 \\
\hline Externalizing problems & $52.14(2.01)^{\mathrm{a}, \mathrm{b}}$ & $48.02(0.70)^{\mathrm{b}}$ & $55.76(2.38)^{\mathrm{a}}$ & $48.61(0.95)^{\mathrm{b}}$ & $4.38 * * *$ & 0.06 \\
\hline \multicolumn{7}{|l|}{ Parents (CBCL) } \\
\hline Internalizing problems & $50.97(1.55)$ & $49.25(1.36)$ & $53.27(1.71)$ & $48.86(1.04)$ & 1.85 & 0.03 \\
\hline Externalizing problems & $53.18(1.87)^{\mathrm{a}, \mathrm{b}}$ & $49.38(1.19)^{\mathrm{b}, \mathrm{c}}$ & $57.16(1.72)^{\mathrm{a}}$ & $46.54(0.85)^{\mathrm{c}}$ & $10.90 * * *$ & 0.13 \\
\hline
\end{tabular}

*** $P<0.001$

$* P<0.05$

${ }^{\mathrm{A}} \mathrm{F}$ values adjusted for the effects of child's gender

Means sharing a subscript in common were not significantly different form each other (Tukey HSD or the Tamhane post-hoc procedure for multiple comparisons)

shows high levels of emotional support and control attempts and low levels of rejection from both parents. A third parenting type, called rejecting-controller (15.8\%), shows the highest levels of rejection and high levels of control attempts from both parents. The last parenting type, the supportive pattern (36.4\%), shows high levels of emotional support and low levels of rejection and control attempts from both parents.

The supportive-controller type is one of the patterns that occur most frequently. Therefore, a parenting pattern characterized by high levels of emotional support, but also high levels of parental control, seems to be a common pattern in Portuguese school-aged children. Regarding this result, it is important to consider two aspects of the studied sample. Firstly, this study focuses on middle childhood children. In middle childhood, parents need to continue supervising, monitoring, and exerting some control over their children's behaviour and daily activities. The existence of considerable parental control in this developmental period may be considered to be an adaptive strategy for providing some structure and safety in the lives of their children. Secondly, it is also necessary to consider the cultural socialization goals of Portuguese parents. Latino cultural values that emphasize interdependence, unity and loyalty between family members (Rudy and Grusec 2006) are, at some degree, present in Portuguese parents, and these cultural values favour the use of higher levels of control over children.

The identification of different patterns of parental rearing styles in this study was done by simultaneously considering mothers' and fathers' parental rearing dimensions. To our knowledge no other study using cluster analysis in order to identify patterns of rearing styles included the assessment of both mothers' and fathers' parental rearing styles.

Results suggest that similar parenting profiles for father and mother are perceived by the children in all four parenting types. The absence of a pattern that included different profiles for mother and father like the traditional type identified in Baumrind's study, may suggest that presently there is an attenuation of traditional gender roles concerning parenting (more harsh and strict parenting style for fathers and more responsive and warm parenting style for mothers). Nevertheless, higher levels of emotional support and control attempts from mother are reported in all patterns, which is consistent with the empirical 
literature that describes mothers as being more involved than fathers in everyday parenting (Castro et al. 1997; Forehand and Nousiainen 1993; Paulson and Sputa 1996; Russel and Russel 1987).

The typology identified in this study shows some similarities with the parenting styles' typology developed by Baumrind (19671, 1989, 1991a, 1991b). The rejectingcontroller pattern characterized by a high level of perceived hostility, punishment, restrictiveness, and intrusiveness is similar to the authoritarian type. The perception of low levels in all three parenting dimensions in the low support pattern suggests lower involvement in parenting roles and some emotional detachment and, therefore, this pattern seems to be similar to the rejecting-neglecting type identified by Baumrind (1989).

In our opinion, the two other patterns, supportive-controller and supportive, do not have a straightforward correspondence to the authoritative and permissive types described by Baumrind. Parents included in both of these types, like the authoritative and permissive parents, are perceived by children as providing warmth, stimulation and acceptance of the child's characteristics. However, in Baumrind typology these two patterns differ in the control/ demandingness dimension in the sense that authoritative parents exert firm control and high maturity demands, and permissive parents make few maturity demands and avoid exercising control. In this study, the dimension of Control, called Control attempts, includes simultaneous indicators of psychological control (for example, control is exercised by engendering guilt), and of behavioural control (for example, practices that monitor and restrict the activities of children), but does not include practices of firm and consistent control and demands for maturity, which were considered in Baumrind's (1989) study.

The second purpose of this study was to examine the associations between the different patterns of parental rearing styles and adjustment. This objective was accomplished by considering the information from various sources, and two main domains of children's behavioural problems evaluated at two separate points in time. The results show that different patterns of parental rearing styles are significantly associated with behavioural problems, adjusting the effects for child gender, and these associations are significant for both informants (parents and teachers) and time periods.

The association between parenting types and adjustment remains significant a year after the first assessment, showing even a slight increase in the magnitude of the effects. The biggest contribution from the parenting types to the subsequent adjustment may be due to the fact that this second assessment period corresponds to a change of school, subjecting children to a greater stress. Consequently, the "family environment" associated with the different parenting types could work as an attenuating or amplifying variable of the risk created by this transition.

In both assessment periods the supportive and supportive-controller types showed more positive results in the different indicators than the low support and rejectingcontroller types. These results suggest that regardless of the control perceived by the child, the perception of high emotional support and low levels of rejection lead to a more positive adjustment, supporting the position that considers these dimensions as universal beneficial attributes of parenting. There was no negative effect of parental overcontrol and intrusiveness when the child perceived high emotional support and low rejection from parents. This result supports the importance of simultaneously considering multiple parenting dimensions and their interactive effects to understand parental rearing influence in children's adjustment. Control practices in the context of a strong emotional bond between parents and child may translate signs of involvement and preoccupation with the child's safety and well-being. This is further supported by the fact that the supportive-controller pattern is relatively common in Portuguese school-aged children. It will be interesting to study if this interactive effect between overcontrol and emotional support is specific to this developmental period and cultural context.

Analysing whether there is specificity in the relationship between different parenting patterns and different dimensions of psychopathology was also an objective of the present study. Recently, Caron et al. (2006) claimed that there is not yet an adequate body of research to support or deny the existence of specificity.

Our results show that negative patterns of parental rearing styles show a stronger association with externalizing problems in comparison to internalizing problems. The influence of parental behaviour in the development of externalizing problems was supported by various studies based both on dimensional approach (e.g. Caron et al. 2006; Muris et al. 2003; Pettit et al. 2001) and on typological approach (e.g. Lamborn et al. 1991) and is emphasized by theoretical perspectives (e.g. Granic and Patterson 2006), which consider parental behaviour as an important etiological factor and perpetrator of anti-social behaviour.

On the other hand, the absence of associations between parental rearing styles and internalizing problems do not confirm the results of previous studies (e.g. Caron et al. 2006; Chen et al. 2000; Gracia et al. 2005; Javo et al. 2004; Muris et al. 2003). However, it should be noted that, with one exception (Caron et al. 2006), these previous studies do not take into account the high correlations between internalizing and externalizing problems. The present study has the advantage of, at the same time, including the assessment of the internalizing problems and 
the assessment of externalizing problems and controlling the association between these two dimensions.

Interestingly, the results of this study are in line with a study that also resorted to the child version of EMBU. Muris et al. (1996) examined the relationship between parental rearing behaviours and psychopathology in three groups of clinically referred children: children with anxiety disorder, children with disruptive disorder and a "control" group, composed of children with a condition not attributable to a mental disorder. Only children with disruptive disorder differed from the "control" group, showing more negative rearing behaviours and less positive rearing behaviours with no significant differences emerging between children with anxiety disorders and children with a condition not attributable to a mental disorder. Therefore, the combined results of both Muris et al. (1996) and the present study results suggest that in future research this issue should be dealt with more deeply.

Lastly, it is important to point out that in spite of finding significant associations between parenting types and adjustment, these associations are of a small magnitude (being the highest $\eta^{2}=0.13$ ). This may be due to the use of cluster analysis to identify "natural groups" concerning parental rearing styles. The groups created with this methodology show more moderate values in the various dimensions of parental styles than the prototype approaches group, which from the start excludes sample elements that show more moderate values.

There are a number of limitations to the current study that should be considered. Firstly, only self-report measures were included in the assessment of parental rearing and adjustment. Observational methodology would enrich the data collected through self-report methodology. However, we avoided the problem of common method variance by including different reporters for parental rearing styles (children) and behaviour problems (teachers and parents). Secondly, the construct of examined parental rearing styles includes the consideration of three parenting dimensions that do not capture the entire complexity of a child's experience of parenting. Namely, it would be interesting to further study the combined effect of these dimensions with the dimension of demandingness, including for that purpose the evaluation of practices of firm control and maturity demands. Thirdly, the sample was composed of participants who were nonclinical. Although children belonging to low support and rejecting-controller parenting types show a relatively higher report of behavioural problems, the majority of children in these groups are still within the normal range. The extent to which the current findings would generalize to clinical samples is unknown. Fourthly, despite the longitudinal prospective design of the study, the direction of effects between negative parental rearing practices and behavioural problems is difficult to ascertain. Parenting dimensions can cause or perpetuate child behavioural problems, specifically externalizing problems. But it is also possible that aggressive children can elicit rejecting behaviours from parents, reduce parent's motivation to be accepting, and promote more controlling and restrictive practices as a form of managing child misbehaviour. Also, parental rearing styles are not the only factors involved in the pathogenesis of behavioural problems. Other risk and protective factors (e.g., genetic factors, child's temperament, mental health status and personalities of parents, marital relation between parents, family characteristics, and other social influences) that interact with parenting factors should be considered in future research.

Despite these limitations, this study has many strengths, including the adoption of a typological approach of parental rearing styles using cluster analysis, the assessment of the mother's and the father's parental rearing dimensions, the large sample, the collection of data from multiple reporters (children, parents, and teachers) and of multiple domains of adjustment (internalizing and externalizing problems), and the longitudinal design. Overall, the results of this study suggest the importance of the typological approach for describing patterns of parental rearing styles that occur naturally in a population of Portuguese school-aged children. The approach followed in the present study had the additional advantage of emphasising the interaction effects between the three parental rearing dimensions, thus promoting a better understanding of the relationship between parenting and behavioural problems. The current data also suggests that the child's developmental level and cultural context should be considered in future studies, focusing on the effects of parental rearing styles. Finally, the evidence that parental rearing patterns show a stronger association with externalizing problems in comparison to internalizing problems should deserve attention in future studies. These studies can examine the question whether there is specificity in the relationship between parenting and child internalizing and externalizing problems, using designs and analytical models that take into account correlation among these forms of psychopathology.

Acknowledgments This research was supported in part by a grant (SFRH/BD/12308/2003) from the Technology and Science Foundation (FCT) provided to the first author. Thanks to children, parents and teachers which participated in the project.

\section{References}

Achenbach, T. M. (1991a). Manual for the Child Behaviour Checklist and 1991 Profile. Burlington, VT: University of Vermont, Department of Psychiatry. 
Achenbach, T. M. (1991b). Manual for the Teachers Report Form and 1991 Profile. Burlington, VT: University of Vermont, Department of Psychiatry.

Baumrind, D. (1967). Child care practices anteceding three patterns of pre-school behaviour. Genetic Psychology Monographs, 75, 43-88.

Baumrind, D. (1971). Current patterns of parental authority. Developmental Psychology Monograph, 4, 1-103. doi:10.1037/ h0030372.

Baumrind, D. (1989). Rearing competent children. In W. Damon (Ed.), Child development today and tomorrow (pp. 349-378). San Francisco: Jossey-Bass.

Baumrind, D. (1991a). Parenting styles and adolescent development. In J. Brooks-Gunn, R. Lerner, \& A. C. Petersen (Eds.), The encyclopedia on adolescence (pp. 746-758). New York: Garland.

Baumrind, D. (1991b). Effective parenting during the early adolescent transition. In P. E. Cowan \& E. M. Hetherington (Eds.), Advances in Family Research (Vol. 2, pp. 111-163). Hillsdale, NJ: Lawrence Erlbaum Associates.

Brenner, V., \& Fox, R. A. (1999). An empirical classification of parenting practices. The Journal of Genetic Psychology, 160, 343-357.

Canavarro, M. C., \& Pereira, A. I. F. (2007a). A percepção dos filhos sobre os estilos parentais educativos: A versão portuguesa do EMBU-C [Childreńs perception about parental rearing styles: The Portuguese version of EMBU-C]. Revista Iberoamericana de Diagnóstico y Evaluación Psicológica, 2, 193-210.

Canavarro, M. C., \& Pereira, A. I. F. (2007b). A avaliação dos estilos parentais educativos na perspectiva dos pais: A versão portuguesa do EMBU-P [Parents evaluation of parental rearing styles: The Portuguese version of EMBU-P]. Teoria. Investigação $e$ Prática, 2, 271-286.

Caron, A., Weiss, B., Harris, V., \& Catron, T. (2006). Parenting behaviour dimensions and child psychopathology: Specificity, task dependency, and interactive relations. Journal of Clinical Child and Adolescent Psychology, 35, 34-45. doi:10.1207/s153 74424jccp3501_4.

Castro, L., Pablo, J., Gómez, J., Arrindell, W. A., \& Toro, J. (1997). Assessing rearing behaviour from the perspective of the parents: A new form of the EMBU. Social Psychiatry and Psychiatric Epidemiology, 32, 230-235. doi:10.1007/BF00788243.

Castro, J., Toro, J., Van Der Ende, J., \& Arrindell, W. A. (1993). Exploring the feasibility of assessing perceived parental rearing styles in Spanish children with the EMBU. The International Journal of Social Psychiatry, 39, 47-57. doi:10.1177/002076 409303900105.

Chen, X., Liu, M., \& Li, D. (2000). Parental warmth, control, and indulgence and their relations to adjustment in Chinese children: A longitudinal study. Journal of Family Psychology, 14, 401419. doi:10.1037/0893-3200.14.3.401.

Cummings, M. E., Davies, P. T., \& Campbell, S. B. (2000). Developmental Psychopathology and family process: Theory, research and clinical implications. New York: Guilford Press.

Darling, N., \& Steinberg, L. (1993). Parenting style as context: An integrative model. Psychological Bulletin, 113, 487-496. doi: 10.1037/0033-2909.113.3.487.

Deater-Deckard, K., Bates, J. E., Dodge, K. A., \& Pettit, G. S. (1996). Physical discipline among African-American and EuropeanAmerican mothers: Links to children externalizing behaviours. Developmental Psychology, 32, 1065-1072. doi:10.1037/00121649.32.6.1065

Deater-Deckard, K., \& Dodge, K. A. (1997). Externalizing problems and discipline revisited: Nonlinear effects and variation by culture, context, and gender. Psychological Inquiry, 8, 161-175. doi:10.1207/s15327965pli0803_1.
Dornbusch, S. M., Ritter, P. L., Leiderman, P. H., Roberts, D. F., \& Fraleigh, M. J. (1987). The relation of parenting style to adolescent school performance. Child Development, 57, 879-894.

Fonseca, A. C., Simões, A., Rebelo, J. A., Ferreira, J. A., \& e Cardoso, F. (1995). O inventário de comportamentos da criança para professores-Teachers Report Form (TRF) [The child behaviour inventory for teachers-Teachers Report Form (TRF)]. Revista Portuguesa de Pedagogia, 29, 81-102.

Fonseca, A. C., Simões, A., Rebelo, J. A., Ferreira, J. A. G., \& Cardoso, F. (1994). Um inventário de competências sociais e de problemas de comportamento em criançase adolescentes-o Child Behaviour Checklist de Achenbach (CBCL) [An inventory of social competence and problems behaviour in children and adolescents-the Child Behaviour Checklist of Achenbach (CBCL)]. Psychologica, 12, 55-78.

Forehand, R., \& Nousiainen, S. (1993). Maternal and paternal functioning: Critical dimensions in adolescent functioning. Journal of Family Psychology, 7, 213-221. doi:10.1037/08933200.7.2.213.

Garmezy, N. (1990). A closing note: Reflections on the future. In J. Rolf, A. Masten, D. Cicchetti, K. Nuechterlein, \& S. Weintraub (Eds.), Risk and protective factors in the development of psychopatology (pp. 527-534). Cambridge: University Press.

Gracia, E., Lila, M., \& Musitu, G. (2005). Rechazo parental y ajuste picológico y social de los hijos. Salud Mental, 28, 73-81.

Granic, I., \& Patterson, G. L. (2006). Toward a comprehensive model of antisocial development: A dynamic systems approach. Psychological Review, 113, 101-133. doi:10.1037/0033295X.113.1.101.

Javo, C., Ronning, J. A., Heyerdahl, S., \& Rudmin, F. W. (2004). Parenting correlates of child behaviour problems in a multiethnic community sample of preschool children in northern Norway. European Child and Adolescent Psychiatry, 13, 8-18. doi: 10.1007/s00787-004-0349-3.

Lamborn, S. D., Mounts, N. S., Steinberg, L., \& Dornbusch, S. M. (1991). Patterns of competence and adjustment among adolescents from authoritative, authoritarian, indulgent, and neglectful families. Child Development, 62, 1049-1065. doi:10.2307/ 1131151.

Maccoby, E. E. (1984). Middle childhood in the context of the family. In W. A. Collins (Ed.), Development during middle childhood: The years from six to twelve (pp. 184-239). Washington, D.C: National Academic Press.

Maccoby, E. E., \& Martin, J. A. (1983). Socialization in the context of the family: Parent-child interaction. In M. Hetherington (Ed.), Handbook of child psychology: Vol. 4. Socialization, personality and social development (pp. 1-101). New York: Wiley.

Mandara, J. (2003). The typological approach in child and family psychlogy: A review of theory, methods and research. Clinical Child and Family Psychology Review, 6, 129-146. doi: 10.1023/A:1023734627624.

Mandara, J., \& Murray, C. B. (2002). Development of an empirical typology of African American family functioning. Journal of Family Psychology, 16, 318-337. doi:10.1037/0893-3200.16. 3.318 .

McIntyre, R. M., \& Blashfield, R. K. (1980). A nearest centroid technique for evaluating the minimum-variance clustering procedure. Multivariate Behavioral Research, 15, 225-238. doi: 10.1207/s15327906mbr1502_7.

Morrison, F. J., \& Cooney, R. R. (2002). Parenting and academic achievement: Multiple paths to early literacy. In J. G. Borkowski, S. L. Ramey, \& M. Bristol-Power (Eds.), Parenting and the child's world: Influences on academic, intellectual, and socialemotional development (pp. 141-160). Mahwah: Lawrence Erlabaum Associates. 
Muris, P., Bögels, S., Meesters, C., van der Kamp, N., \& van Oosten, A. (1996). Parental rearing practices, fearfulness, and problem behaviour in clinically referred children. Personality and Individual Differences, 21, 813-818. doi:10.1016/01918869(96)00119-5.

Muris, P., Meesters, C., \& van der Berg, S. (2003). Internalizing and externalizing problems as correlates of self-reported attachment style and perceived parental rearing in normal adolescents. Journal of Child and Family Studies, 12, 171-183. doi: 10.1023/A:1022858715598.

O'Connor, T. (2006). Annotation: the 'effects' of parenting reconsidered: Findings, challenges, and applications. Journal of Psychology and Psychiatry, 43, 555-572. doi:10.1111/14697610.00046.

Paulson, S. E., \& Sputa, C. L. (1996). Patterns of parenting during adolescence: Perceptions of adolescents and parents. Adolescence, 31, 369-381.

Pereira, A. I. F., Canavarro, M. C., Mendonça, D. V., \& Cardoso, M. F. (2005). Validação de um instrumento de avaliação do apoio social em crianças-a versão portuguesa do my family and friends. [Validation of an instrument for the evaluation of children's social support-the Portuguese version of my family and friends]. Revista Ibero-Americana de Diagnóstico Y Evaluación, 20, 105-131.

Pettit, G. S., Laird, R. D., Dodge, K. A., Bates, J. E., \& Criss, M. M. (2001). Antecedents and behaviour-problem outcomes of parental monitoring and psychological control in early adolescence.
Child Development, 72, 583-598. doi:10.1111/1467-8624. 00298.

Rudy, D., \& Grusec, J. E. (2006). Authoritarian parenting in individualist and collectivist groups: associations with maternal emotion and cognition and children's self-esteem. Journal of Family Psychology, 20, 68-78. doi:10.1037/0893-3200.20.1.68.

Russell, G., \& Russell, A. (1987). Mother-child and father-child relationships in middle childhood. Child Development, 58, 1573-1585. doi:10.2307/1130696.

Shanahan, L., McHale, S. M., Crouter, A. C., \& Osgood, D. W. (2007). Warmth with mothers and fathers from middle childhood to late adolescence: Within-and between-families comparisons. Developmental Psychology, 43, 551-563. doi:10.1037/ 0012-1649.43.3.551.

Shek, D. T. L. (2000). Differences between fathers and mothers in the treatment of, and relationship with, their teenage children: Perceptions of Chinese adolescents. Adolescence, 35, 135-147.

Steinberg, L., Lamborn, S. D., Darling, N., Mounts, N. S., \& Dornbusch, S. M. (1994). Over-time changes in adjustment and competence among adolescents from authoritative, authoritarian, indugent and neglectful families. Child Development, 65, 754770. doi: $10.2307 / 1131416$.

Stewart, S. M., \& Bond, M. H. (2002). A critical look at parenting research from the mainstream: Problems uncovered while adapting western research to non-western cultures. The British Journal of Developmental Psychology, 20, 379-392. doi: $10.1348 / 026151002320620389$. 